\title{
Studies on the Effect of Bacteriophage Lysate of Pasteurella multocida on Serum Protein Levels in Rabbits
}

\author{
Yanglem Pushpa and Hari Mohan Saxena*
}

Department of Veterinary Microbiology, College of Veterinary Science, Guru Angad Dev

Veterinary and Animal Sciences University (GADVASU), Ludhiana 141004 Punjab, India

*Corresponding author

\section{A B S T R A C T}

Keywords

Hemorrhagic septicemia, Pasteurella multocida, Bacteriophage, Phage lysate, Vaccine, Host response

Article Info

Accepted:

15 May 2019

Available Online:

10 June 2019
The study was undertaken to evaluate the protein levels in rabbits affected by a lysate vaccine developed from Pasteurella multocida grown under iron-restricted conditions and lysed by a bacteriophage. Serum proteins include immunoglobulins and complement which mediate humoral immune response and an assessment of protein levels can be of clinical relevance being an indicator of humoral immune response. Two groups of rabbits were immunized with lysate vaccine (LV) and conventional alum precipitated killed HS vaccine $(\mathrm{CV})$ and blood was collected at various days post - immunization (DPI). The serum protein concentration in lysate vaccinated rabbits $(2.74+1.436)$ was significantly higher $(\mathrm{p}<0.05)$ than the conventional vaccinated rabbits $(0.73+0.230)$ at $30 \mathrm{DPI}$. The increased total protein could be due to increase in various components like the acute phase proteins, immunoglobulins, lymphokines, mediators of inflammation and complement activation because of the antigenic stimulus provided by the phage lysate.

\section{Introduction}

The widely used alum precipitated heat killed vaccine for Hemorrhagic Septicemia induces only a short duration of immunity (Qureshi and Saxena, 2014). The loss of immunogenic epitopes due to harsh methods (heat, chemicals, UV rays) used for killing of bacteria in the conventional heat killed vaccines has been circumvented in the new candidate vaccine developed recently in our laboratory (Saxena and Qureshi, 2013;
Qureshi and Saxena, 2017) by using a lytic bacteriophage for killing the bacteria. Additional immunogenic epitope in the form of iron uptake receptor has also been induced in the new vaccine.

Serum proteins include immunoglobulins and complement which mediate humoral immune response. An assessment of protein levels can be of clinical relevance being an indicator of humoral immune response. The present study was conducted to compare the serum protein 
concentration of rabbits vaccinated with the bacteriophage-lysed Pasteurella multocida bearing iron uptake receptors with those vaccinated with the conventional (heat killed, alum precipitated) vaccine for Pasteurellosis.

\section{Materials and Methods}

\section{Phage lysate}

We prepared a Pasteurellaphage lysate using $P$. multocida (B:2) grown under iron restricted conditions using 2', 2' dipyridyl followed by lysis with a lytic Pasteurellaphage to immunize the rabbits to assess its potential as a vaccine for Hemorrhagic Septicemia in cattle as per the method described earlier (Qureshi and Saxena, 2017).

\section{Immunizations in rabbits}

The permission of IAEC was obtained and IAEC guidelines were followed. Adult Soviet Chinchilla rabbits were procured from the Small Animal House, Department of Livestock Production Management, GADVASU, Ludhiana. The rabbits were divided into two groups viz., group I (lysate vaccine, $\mathrm{n}=3$ ) and group II (conventional vaccine, $n=3$ ).

Group I rabbits were immunized with $0.1 \mathrm{ml}$ of phage lysate of $P$. multocida grown under iron restricted conditions through subcutaneous route whereas group II received $0.1 \mathrm{ml}$ of conventional HS vaccine (alum precipitated vaccine) obtained from the Punjab Veterinary Vaccine Institute, Ludhiana.

Blood was collected from rabbits in both the groups on 0 day and 30, 60, 90, 120- and 210days post immunization (DPI) and sera were separated, pooled and stored at $-20^{\circ} \mathrm{C}$ until used.

\section{Estimation of total protein levels in serum samples}

The total protein content in the serum samples of rabbits collected at $0,30,60,90,120$, and 210 days post-inoculation were estimated by the Bradford assay using a Protein Estimation Kit (Genei, Bangalore). The absorbance (OD) at $595 \mathrm{~nm}$ was measured using a Perkin Elmer Lambda 25 UV/VIS spectrophotometer.

\section{Results and Discussion}

Haemorrhagic Septicaemia (HS) caused by Pasteurella multocida serotype B: 2 is an acute, fatal disease of cattle and buffaloes with high morbidity and mortality rates in cattle and buffaloes in India and other Asian countries. In India, losses of USD 130,000 due to haemorrhagic septicaemia have been reported (Singh et al., 2014). The annual losses to the North American cattle industry due to the disease have been estimated to the tune of US\$ 800 million and $\$ 1.4$ million in Laos (FAO, 1991), US\$ 400-6000 in Indonesia, US\$ 1.0 million in Malaysia (Drummond et al., 1981), US\$2.3 million in Bangladesh (Ahmed, 1996) and US\$6 million in Srilanka (De Alwis and Vipulasiri, 1981).

Vaccination against Haemorrhagic Septicaemia is widely practiced in most of the countries experiencing the disease (Ahmad et al., 2014). The commercially used formalinkilled alum-precipitated vaccine and oil emulsion vaccines for HS control, suffer from poor potency, efficacy, safety and other problems (Rahman et al., 2016; Ray and Singh, 2013). In spite of use of multivalent vaccines and annual vaccinations in endemic areas outbreaks of disease are recorded every year (Gowrakkal et al., 2014). In recent decade vaccines with improved immunity like intranasal live attenuated vaccine, $P$. multocida B:3,4 isolated from a fallow deer, attenuated live aroA gene mutant vaccine 
derived from a virulent $P$. multocida B:2 isolate (strain 85020) have been reported (Hodgson et al., 2005; Myint et al., 2005; Rafidah et al., 2011; Saleem et al., 2014). For effective implementation of HS control program in India, a safe and efficacious vaccine to provide long lasting protection needs to be developed (Ray and Singh, 2015).

\section{Serum protein concentrations in vaccinated rabbits}

The total protein levels in sera of rabbits vaccinated with the phage lysate and conventional vaccines were estimated by Bradford assay using a commercially available kit. The total protein levels in the lysate vaccinated rabbits were $1.71+0.208$, $2.74+1.436,1.59+0.023,1.40+0.574,0.97$ +0.445 and $1.500+0.542$ at $30,60,90,120$, 150 and 180 DPI respectively. The corresponding values of total serum proteins in conventional vaccinated rabbits were 1.55 $+0.448,0.73+0.230,1.64+0.544,0.78+$
$0.192,0.79+0.19$ and $1.28+0.375$ at 30,60 90, 120, 150 and $180 \mathrm{DPI}$, respectively. The total serum protein level induced by phage lysate at 30D was significantly higher $(\mathrm{p}<0.05)$ than that induced by conventional vaccine at $30 \mathrm{D}, 90 \mathrm{D}$ and $120 \mathrm{D}$. The total serum protein was found to be highest in lysate vaccinated rabbits and lowest in conventional vaccinated rabbits at 30 days post-inoculation (Table 1).

The protein level in LV rabbits was found to gradually decrease by 120 DPI while in conventional vaccinated rabbits it increased initially by 60 DPI followed by gradual decrease till 120 DPI. The serum protein level was much higher in case of lysate vaccinated than $\mathrm{CV}$ rabbits during the period of observation (Fig. 1 and 2). The other differences between the two groups of rabbits regarding mean total protein values at different days were found to be nonsignificant.

Fig.1 Protein levels in sera of rabbits vaccinated with phage lysate or commercial vaccine for Hemorrhagic Septicemia

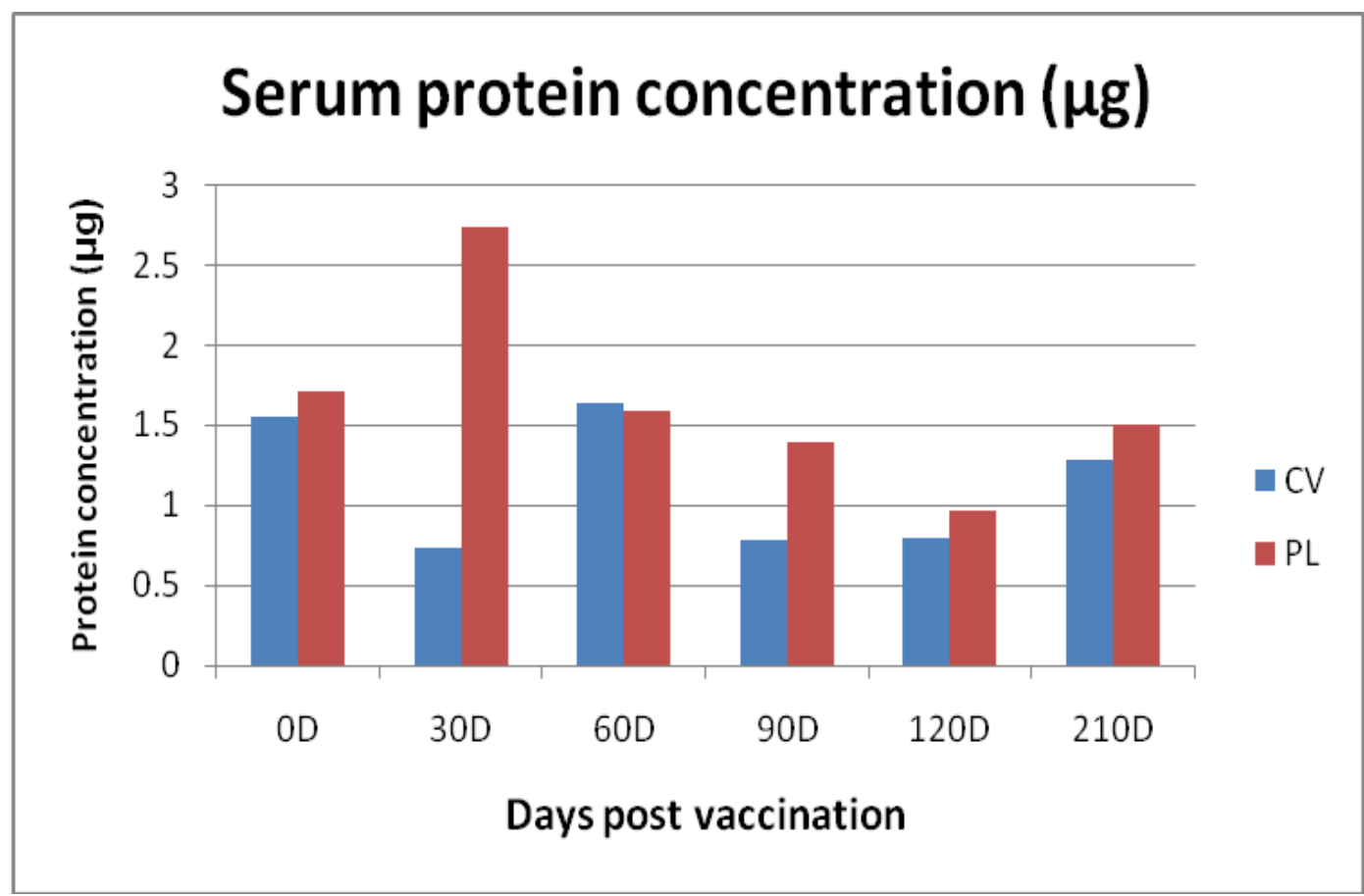


Fig.2 Serum protein concentrations in lysate or conventional vaccinated rabbits

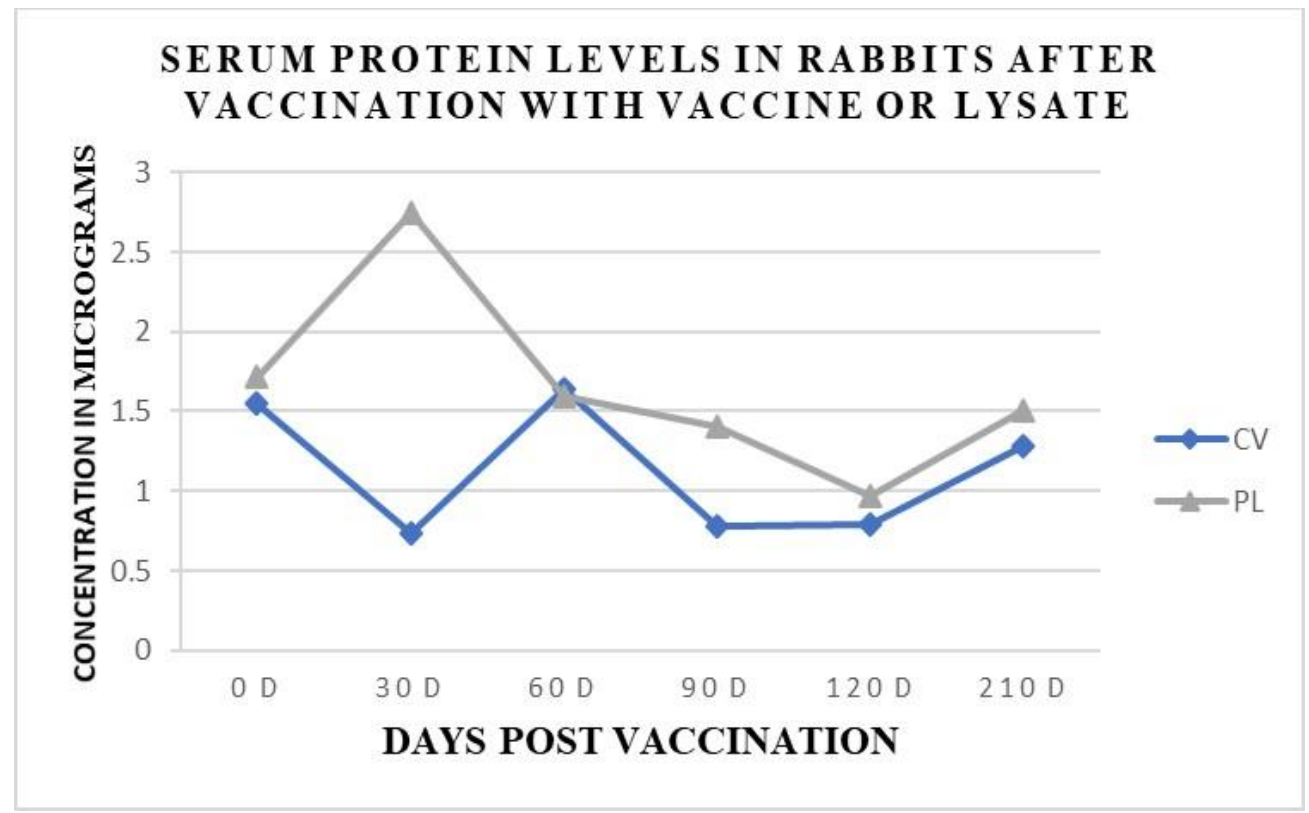

Table.1 Total protein concentration in sera of rabbits vaccinated with phage lysate or commercial vaccine for Hemorrhagic Septicemia

\begin{tabular}{|c|c|c|c|c|c|c|c|c|c|c|c|c|}
\hline \multirow{3}{*}{$\begin{array}{l}\text { S. } \\
\text { no. }\end{array}$} & \multicolumn{12}{|c|}{ Protein concentration $(\mu \mathrm{g})$} \\
\hline & \multicolumn{2}{|l|}{ O D } & \multicolumn{2}{|l|}{$30 \mathrm{D}$} & \multicolumn{2}{|l|}{$60 \mathrm{D}$} & \multicolumn{2}{|l|}{$90 \mathrm{D}$} & \multicolumn{2}{|c|}{$120 \mathrm{D}$} & \multicolumn{2}{|c|}{$210 \mathrm{D}$} \\
\hline & CV & PL & CV & PL & CV & PL & CV & PL & CV & PL & CV & PL \\
\hline 1 & 1.91 & 1.8 & 0.50 & 1.2 & 1 & 1.5 & 0 & 0.93 & 0.58 & 1.26 & 1.07 & 19 \\
\hline 2 & 1.70 & 1.2 & 0.75 & 4.0 & 2.2 & 1.6 & 0 & 2.04 & 0.84 & 0. & 1.72 & 13 \\
\hline 3 & 1.05 & 1.8 & 0.96 & 2.9 & 1.4 & 1.5 & 0. & 1.2 & 0.95 & 1.20 & 1.0 & 1.19 \\
\hline $\begin{array}{l}\text { Mean } \\
\pm \text { SD }\end{array}$ & $\begin{array}{l}1.55 \\
\pm \\
0.448\end{array}$ & $\begin{array}{l}1.71 \\
\pm \\
0.208\end{array}$ & $\begin{array}{l}0.73 \\
\pm \\
\mathbf{0 . 2 3 0}\end{array}$ & $\begin{array}{l}2.74 \\
\pm \\
1.436\end{array}$ & $\begin{array}{l}1.64 \\
\pm \\
\mathbf{0 . 5 4 4}\end{array}$ & $\begin{array}{l}1.59 \\
\pm \\
\mathbf{0 . 0 2 3}\end{array}$ & $\begin{array}{l}0.78 \\
\pm \\
0.192\end{array}$ & $\begin{array}{l}1.40 \\
\pm \\
0.574\end{array}$ & $\begin{array}{l}0.79 \\
\pm \\
0.19\end{array}$ & $\begin{array}{l}0.97 \\
\pm \\
\mathbf{0 . 4 4 5}\end{array}$ & $\begin{array}{l}1.28 \\
\pm \\
\mathbf{0 . 3 7 5}\end{array}$ & $\begin{array}{l}1.500 \\
\pm \\
\mathbf{0 . 5 4 2}\end{array}$ \\
\hline
\end{tabular}

Rabbits, as experimental model for HS have been used by many workers (Bain et al., 1982; Yadev and Ahooja, 1983). Chaudhuri et al., (2012) proposed rabbit as a better laboratory animal model for studying immunogenic properties of an antigen against Pasteurella multocida, causing HS. Vaccine containing IROMPS of iron regulated protein of $P$. heamolytica A: 2 have been reported to enhance protection against experimental Pasteurellosis in lambs (Gilmour et al., 1991). Antibodies to IROMPs from sera of specific pathogen free lambs against whole cell antigens of $P$. haemolytica A2 grown under iron-restricted conditions have been reported in the immunoblots of animals immunized with sodium salicylate extract of iron regulated proteins.

Study revealed that Mannheimia haemolytica A2 and A7 serotype combination expressing iron regulated outer membrane protein as a vaccine gave significant protection against homologous strains on intratracheal challenge 
exposure to Pasteurella in sheep (Tesfaw et al., 2014).

Summary and Conclusions are as follows:

The currently available alum precipitated HS vaccine (conventional vaccine) induces a short duration of immunity and the immune response is of low magnitude occasionally resulting in vaccination failure and outbreaks of disease in vaccinated animals. In the present study, a novel phage lysate vaccine derived from $P$. multocida grown under ironrestricted conditions followed by lysis with a genus specific lytic bacteriophage was used for immunization of rabbits and the immune response induced was compared with that of conventional vaccine. The lysate vaccinated rabbits had significantly $(\mathrm{p}<0.05)$ higher serum protein levels than the conventional vaccinated rabbits at various intervals postimmunization. Although the preliminary results obtained in the present study indicate the promise of the novel lysate vaccine, further studies on larger number of animals are required to get a conclusive picture.

\section{Acknowledgements}

The study was carried out under a project (PI: Prof. H M Saxena) funded by the UGC. The authors are thankful to Dr. Sabia Qureshi for help.

\section{References}

Pushpa Y, Qureshi S and H M Saxena (2016). Some immunological studies on a new vaccine derived from bacteriophage lysate of Pasteurella multocida in mice. Indian Journal of Animal Research 51(6):1057-1061.

Qureshi S and Saxena HM (2014) Estimation of antibody titres in cattle vaccinated with Haemorrhagic Septicaemia alum precipitated vaccine by MAT, IHA and Mab-ELISA. Veterinary World 7(4): 224-228.

Qureshi S and Saxena HM, 2017. A novel phage-based marker vaccine and diva assay for haemorrhagic septicaemia in bovines. Pakistan Veterinary Journal 37(1): 95-99.

Saxena HM and Qureshi S (2013) Bacteriophage based therapeutic vaccines for bacterial diseases: A new dimension in immunobiological and nanotherapeutic development. In Sultana, M., Raina, R., Verma, PK., Parwez, S. and Gupta, SK (2013) Biopharmaceuticals and Nanotechnology in Therapeutics - From Life to Life. SKUAST, Jammu pp 5257.

\section{How to cite this article:}

Yanglem Pushpa and Hari Mohan Saxena. 2019. Studies on the Effect of Bacteriophage Lysate of Pasteurella multocida on Serum Protein Levels in Rabbits. Int.J.Curr.Microbiol.App.Sci. 8(06): 1971-1975. doi: https://doi.org/10.20546/ijcmas.2019.806.234 